\title{
Ossifying pulmonary granulomatosis due to larvae of ascaris
}

\author{
H. S. BAAR ${ }^{1}$ AND J. GALINDO \\ From the Department of Pathology, Pineland Hospital and Training Centre, \\ Pownal, Maine, U.S.A.
}

SYNOPSIS A unique case of ossifying pulmonary granulomata is described in which the presence of larvae of Ascaris lumbricoides within the granulomata was demonstrated by means of immunofluorescence.

The migration of larvae of Ascaris lumbricoides from the intestine through the lungs and bronchial tree into the oesophagus and back into the intestine is a well-known feature of the life cycle of this nematode. The passage through the lungs remains often symptomless, but, in an investigation on experimental infection in man, Takata (1951) found cough in $71.4 \%$ of those infected with human ascaris and in $68.4 \%$ of those infected with pig ascaris. If eggs are fed to a rat or guinea-pig with a little water, the animal shows, after a few days, sneezing and laboured respiration. In many cases of Loeffler's syndrome, the transient benign eosinophilic infiltration of the lungs, and also in tropical eosinophilia (Beaver and Danaraj, 1958) ascaris was found to be the causative organism. Keller, Hillstrom, and Gass (1932) state that the changes seen on radiological examination, which have been attributed to the migration of ascaris larvae, are similar to those seen in the childhood type of hilar tuberculosis and may also resemble the changes which occur following repeated non-specific infections of the lungs. Practically nothing is known of the pathological basis of pulmonary symptoms in ascaris infestation. Beaver and Danaraj found in their case thickening of the alveolar walls and infiltration with various types of leucocytes and partial organization of exudate with fibroblasts in the alveoli. In experimental animals, haemorrhage into the alveoli and respiratory bronchioli, inflammation of bronchial and peribronchial tissues, and heavy muco-purulent exudation into the bronchioles were found. 'The symptoms resulting from such infections are transient, however, because $A$. lumbricoides larvae that fail to make the migration from lungs or other tissues die within a few weeks and are destroyed, at least in experimental animals' (Beaver and Danaraj, 1958).

${ }^{1}$ Present address: 33, Sandon Road, Birmingham 17, England.

Received for publication 10 June 1965.
The following is the description of a unique case with pulmonary ossification and multiple pulmonary granulomata in which larvae of Ascaris were demonstrated immunofluorescently.

\section{CASE REPORT}

O.B., a man, born on 24 April 1893, was admitted to the Pineland Hospital on 10 February 1925. There were no details of fits developing early in infancy, but they began at the age of 5 months. He was sent to school, but attended only one year because of fits and low mentality. On admission, the right leg was atrophic, with chronic ulcers. The right foot was smaller than the left and some-

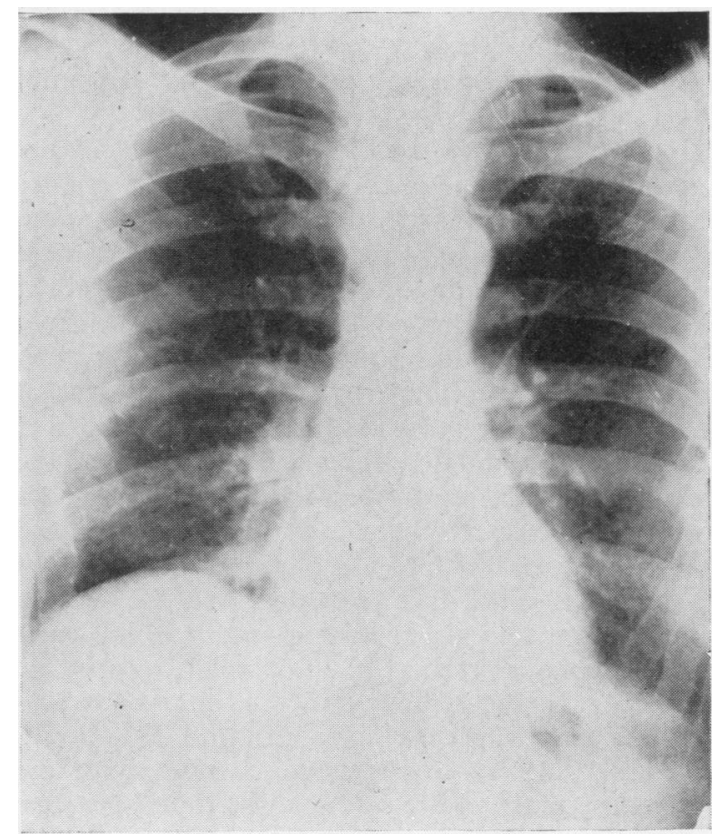

FIG. 1. Radiograph of chest on 26 December 1962. 
what deformed. He developed bilateral cataracts. The $x$-ray examination of lungs was repeatedly negative until 16 June 1958, when mottling of the lung fields was reported. Repeated examination of gastric lavage was negative for tubercle bacilli. The lung fields were clearing, but Dr. David Davidson's $x$-ray report on 26 December 1962 stated: 'increased marking and fine mottling throughout the right lung field and denser markings in the right cardio-hepatic angle. Some finer linear markings can be seen in the lower left lung' (Fig. 1). On 21 November 1961 , an $x$-ray examination revealed a hiatus hernia and there was some suspicion of duodenal ulcer. In September 1962 , the patient fell out of bed and sustained a fracture of the neck of the right femur. The head of the femur was removed at operation. For about one week before death, he became increasingly weak and could not take food. Finally, he developed stertorous respirations, became cyanosed and stuporous. There was no fever, except terminally $\left(102 \cdot 8^{\circ} \mathrm{F}\right.$.). He died on 29 December 1962 at 3 a.m.

\section{POST-MORTEM REPORT}

At necropsy the body was that of a strongly-built, white male of $192 \mathrm{~cm}$. body length. All other measurements were corresponding, except the spina iliaca anterior superior to the lower border of the patella which was, on the right side, $3 \frac{1}{2} \mathrm{~cm}$. shorter than that on the left side. The circumference of the head was $57 \mathrm{~cm}$.

The necropsy findings may be summarized as acute purulent bronchitis and bronchiolitis, pulmonary ossification, hypertrophy of the right ventricle of the heart, myocardial infarctions, septic spleen, hiatus hernia, and senile atrophy of frontal lobes of the brain.

The right lung weighed $700 \mathrm{~g}$. and the left $470 \mathrm{~g}$. There was a pale yellowish exudate in the smaller bronchi and bronchioli. Loose adhesions were present between the pulmonary and costal pleurae on both sides, more on the right. There were a number of hard, apparently calcified, and probably ossified, nodules and spicules in the right lung (Fig. 2), and both lungs showed extensive areas of collapse. A soft, hyperaemic lymph node, $5 \times 3 \times 1$ $\mathrm{cm}$., was seen at the bifurcation but none of the tracheo-bronchial and mediastinal lymph nodes showed evidence of tuberculosis. The heart weighed $290 \mathrm{~g}$. The maximal thickness of the left ventricle was $10 \mathrm{~mm}$., that of the right ventricle $5 \mathrm{~mm}$. There was a mild atheromatosis of the aorta and proximal parts of the coronary arteries. In the cranial parts of the ventricular myocardium and the interventricular septum there were small, grayish areas. Histologically, both lungs showed identical changes, but these were considerably more severe in the right lung than in the left. The smaller bronchi and bronchioli were dilated and filled with masses of polymor-

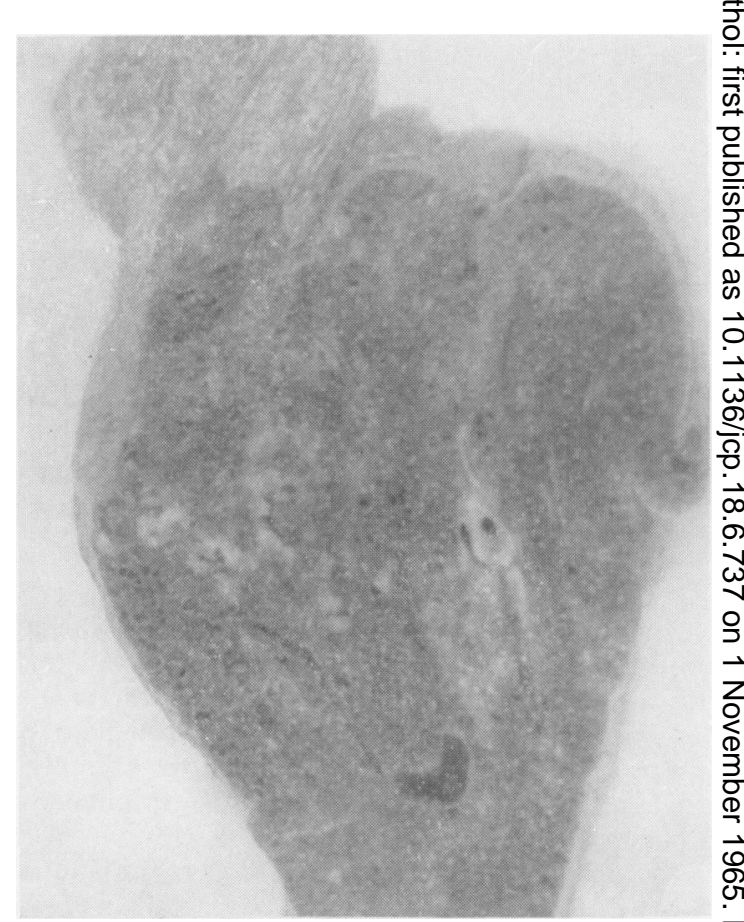

FIJ. 2. Gross appearance of lower lobe of right lung. Bone trabeculae are conspicuous by their whiteness.

phonuclear leucocytes and patches of homogene-

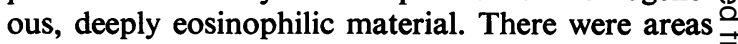
of ulceration in the bronchial walls. The ulceration $\overline{0}$ affected in many places only the epithelial lining, while in others it penetrated through the elastic and muscle layers. Almost all bronchi and bronchioli were surrounded by cuffs of densely-packed, small, round cells. Here and there, a dilated bronchus was:surrounded by large cells with a clear or foamy cytoplasm resembling xanthoma cells. The respiratory tissue showed alternating areas of atelectasis and of emphysema. In numerous, but small, patcheso the alveoli were packed with polymorphonuclear leucocytes. Here and there, a hyaline membrane? was seen. Scattered throughout the interstitial tissue were bone trabeculae, some seen in longi- $\sigma$ tudinal section, others in cross section. Most of the $N$ trabeculae were formed by compact bone (Figs. $3 \mathrm{~N}$ and 5) and only an occasional one showed a fattyo bone marrow, surrounded by a shell of Haversian bone (Fig. 4). All trabeculae showed a broad osteoid seam. More numerous than the bone trabeculae were circumscribed granulomata varying in diameter 0 between 50 and $700 \mu$, and within them peculiar eosinophilic bodies were seen. Some appeared 'worm-like', tapering towards the ends, and struc- $\frac{\mathbb{\Phi}}{\mathbb{D}}$ tureless. Others were eosinophilic rings. In the 


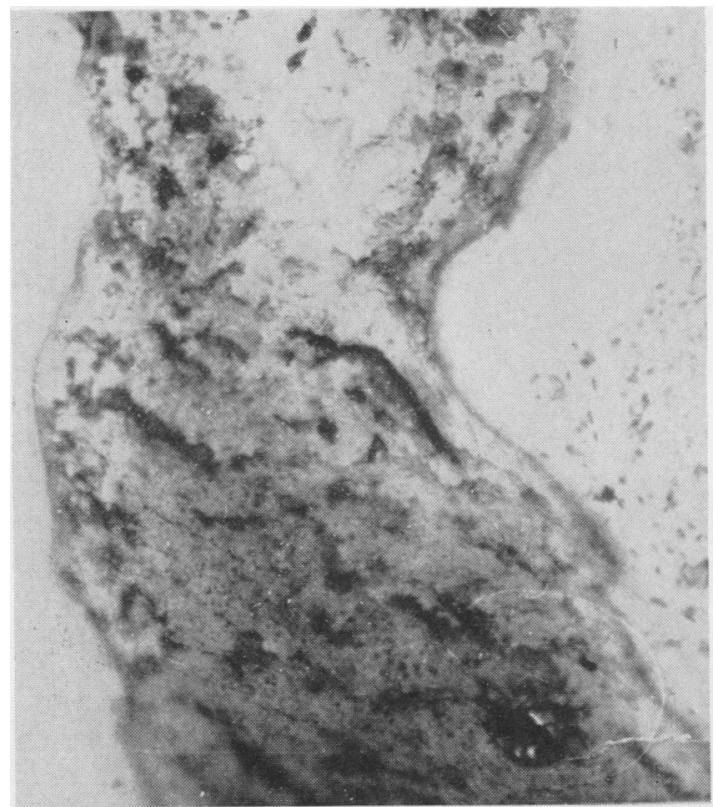

FIG. 3. Bone trabecula in lung. Haematoxylin and eosin $\times 150$.

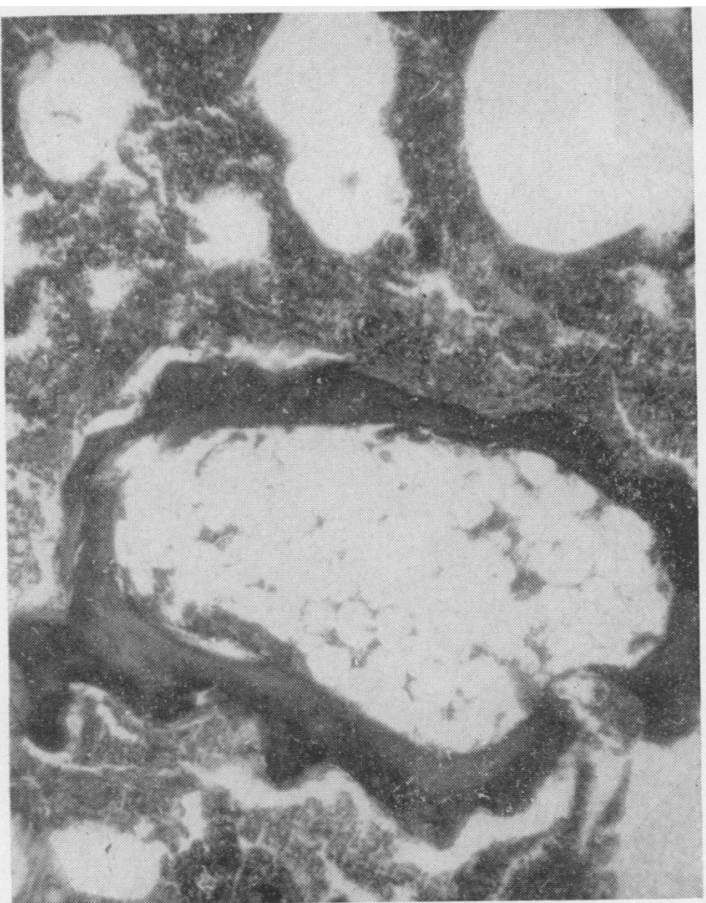

FIG. 4. Bone in lung with fatty bone marrow cavity. Haematoxylin and eosin $\times 150$. centres of the vermiform bodies and of the rings, which were apparently their cross sections, an empty space was seen. There were granulomata with a single vermiform body and others with several. Occasionally, a group of a few vermiform bodies within a granuloma was surrounded by a collagenous capsule. With van Gieson the vermiform bodies stained pale pink, in contrast to the deep red collagenous fibres of the granuloma. With Heidenhain's azan, they stained blue, but also paler than collagen. With Foot's silver impregnation (without

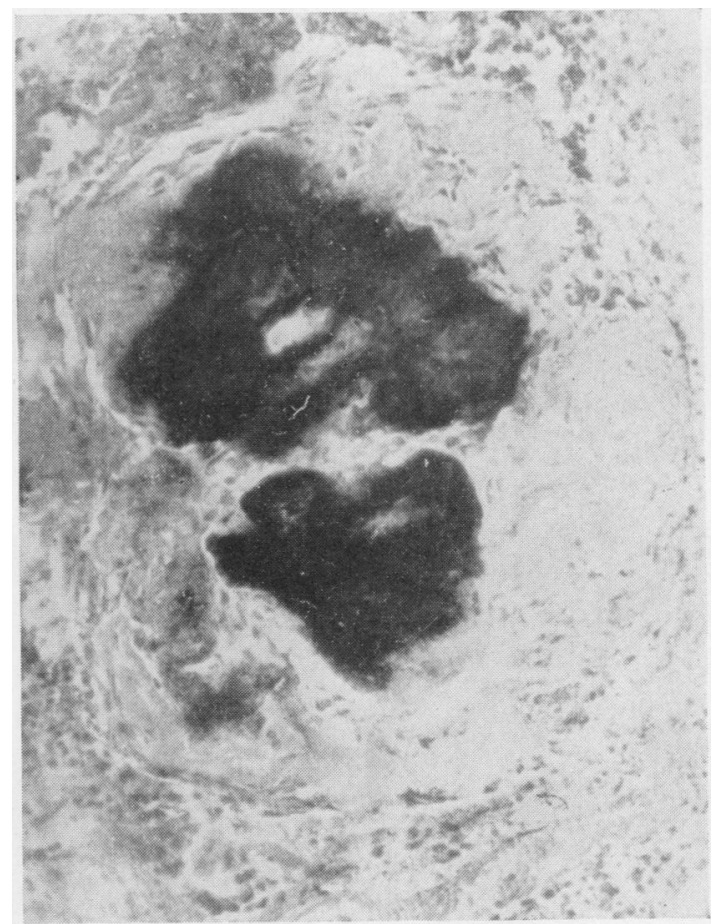

FIG. 5. Calcification and ossification in pulmonary granuloma. Haematoxylin and eosin $\times 150$.

counterstain) the vermiform bodies stained pale pink, contrasting with the abundant black reticulin fibres. Apart from the vermiform and annular bodies there were, in the granulomata, irregular, coarse granules, apparently resulting from disintegration of the former (Figs. 6-8). All granulomata contained numerous macrophages packed with anthracotic pigment. Such macrophages were present around the eosinophilic bodies and often, also, within the central cavity. In a few places, the latter contained also altered red blood cells and/or haemosiderotic pigment (Fig. 9). The granulomatous tissue consisted of histiocytes, lymphocytes, fibroblasts, and an occasional foreign body giant cell. Abundant haemosiderotic pigment 


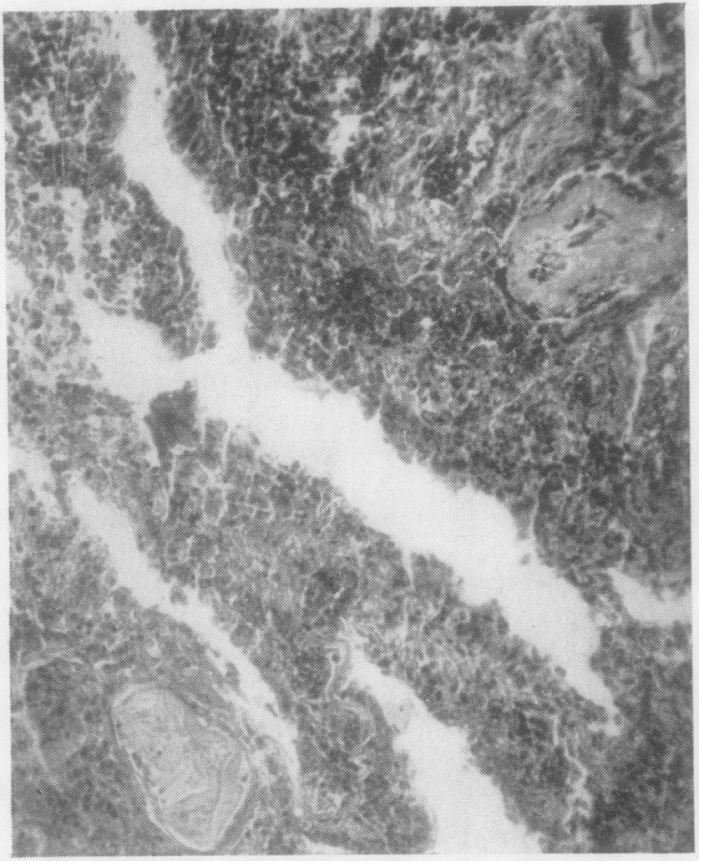

FIG. 6.

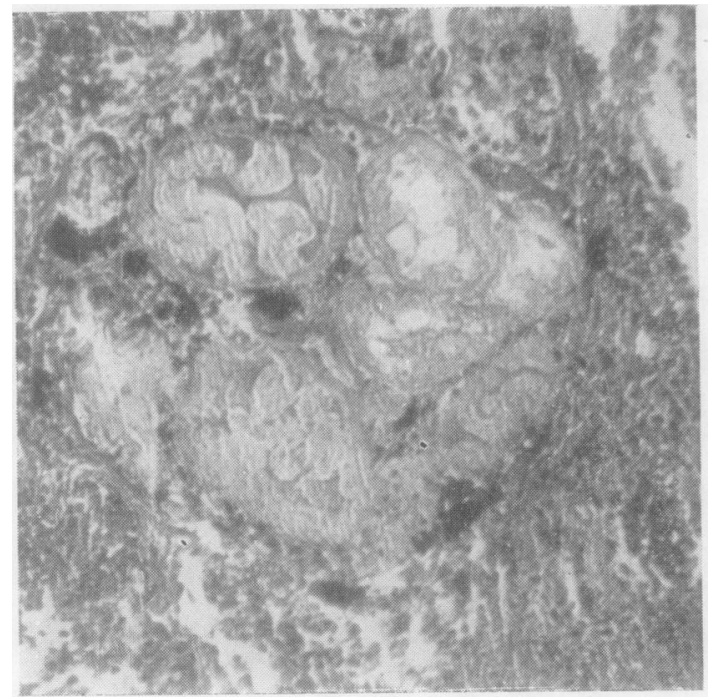

FIG. 7.

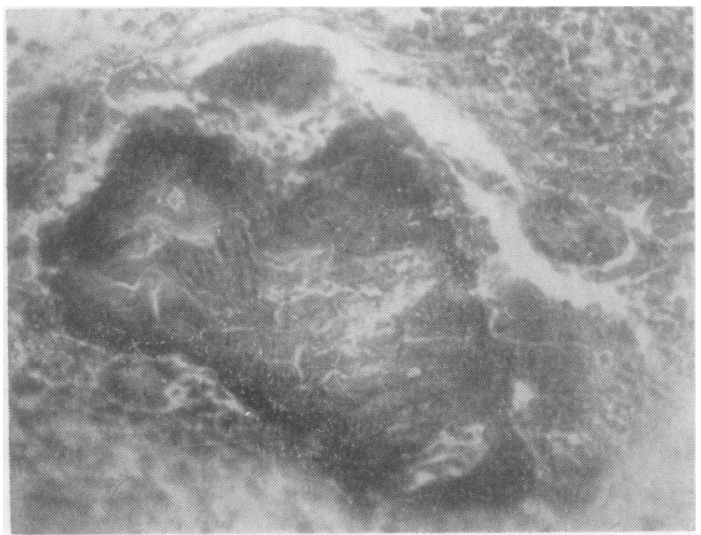

FIG. 10 .

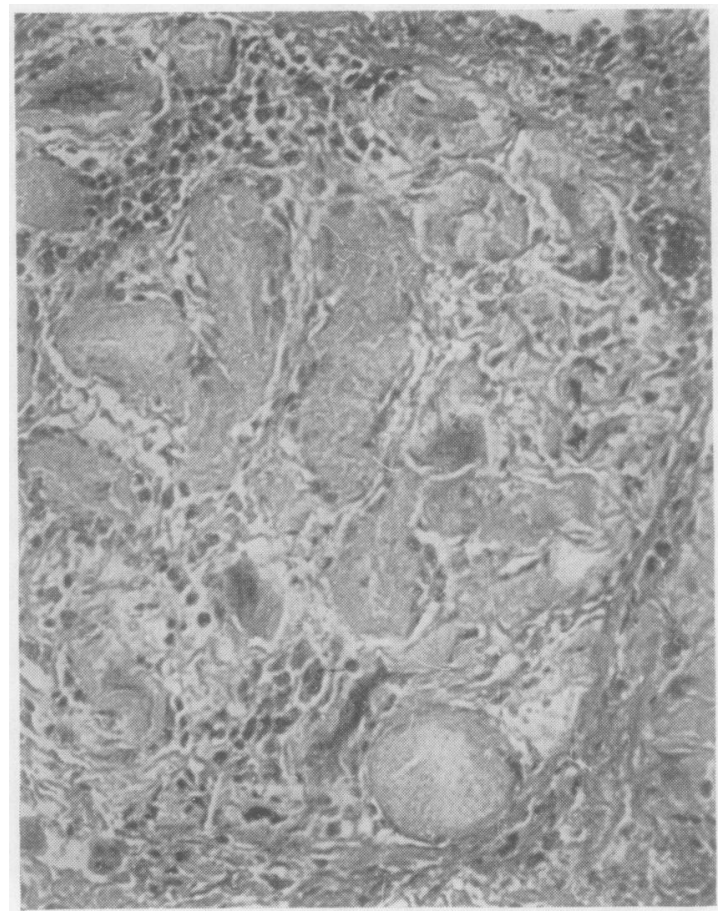

FIG. 8.

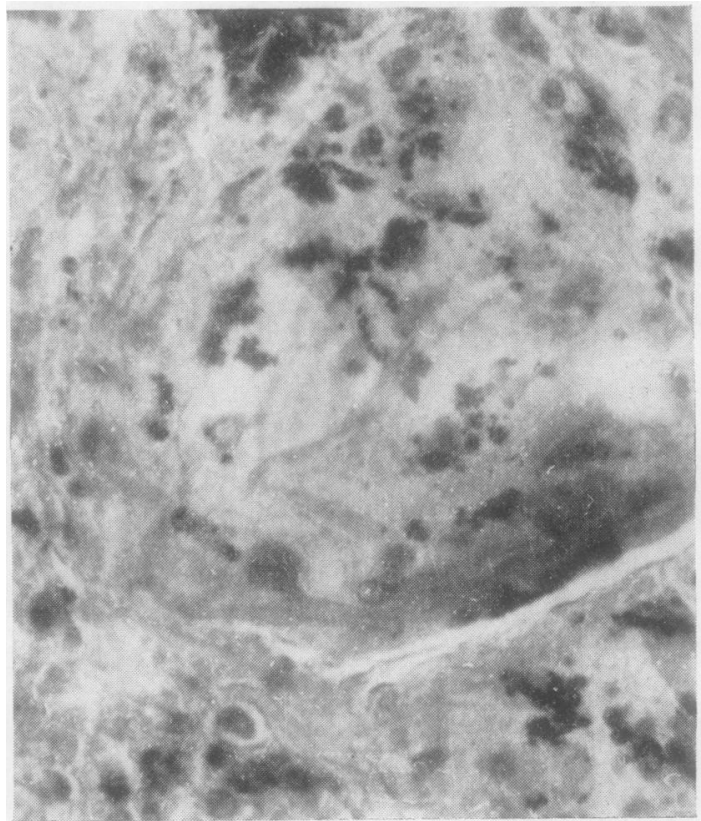

FIG. 9.

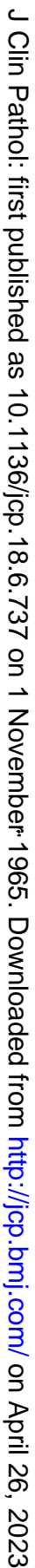

FIG. 6. Two small pulmonary granulomata with larvae of Ascaris lumbricoides. Haematoxylin and eosin $\times 150$.

FIG. 7. Large pulmonary granuloma with several larvae of Ascaris lumbricoides. Haematoxylin and eosin $\times 150$. FIG. 8. Pulmonary granuloma with vermiform bodies. $\frac{\overrightarrow{+}}{\mathrm{D}}$ Haematoxylin and eosin $\times 150$.

FIG. 9. Anthracotic and haemosiderotic pigment pulmonary granuloma. Prussian blue $\times 150$.

FIG. 10. Completely calcified but not yet ossified pul융 monary granuloma. Haematoxylin and eosin $\times 150$. 
was also present outside the granulomata and most of the anthracotic pigment gave a positive Prussian blue reaction. In an occasional granuloma there was calcification without or with beginning ossification (Fig. 10). The pulmonary arteries showed myoelastic hypertrophy.

The heart showed hypertrophy of the right ventricle and areas of myocardial infarction. The histological examination of other organs furnished no additional information to that found on gross examination, except for post-epileptic changes in the brain.

\section{IDENTIFICATION of $A$. lumbricoides}

The appearance of the eosinophilic 'vermiform' bodies in the granulomata suggested dead larvae of Ascaris lumbricoides. It was, therefore, decided to test this surmise by means of immunofluorescence. Specific antigens were isolated from Ascaris lumbricoides, var. suum, by Kent (1960), by Campbell (1936), and by others. Helminthic antigens were discussed at a symposium of the New York Academy of Sciences in 1963. Kent (1960) isolated six distinct antigenic groups in aqueous extracts of ascaris, using paper and agar gel electrophoresis, column chromatography, and double agar diffusion techniques. There is a close relationship between larvae and adult helminthic antigens and animals were successfully vaccinated against parasitic nematodes by exposure to irradiated larvae (Jarrett, Jennings, McIntyre, Mulligan, and Urquhart, 1960).

We immunized six rabbits by intramuscular injections of an aqueous extract of larvae of Ascaris suis. One rabbit received nine injections at weekly intervals, one, 10 injections, and four, 12 injections. Each injection consisted of $1 \mathrm{ml}$. of the ascaris extract and $1 \mathrm{ml}$. of Freund's adjuvant. One week after the last injection, the rabbits were bled and the serum separated. Half of the pooled serum was conjugated with fluorescein-iso-thiocyanate according to directions given by Chadwick and Fothergill (1962). The other half was not conjugated and used for the sandwich technique according to directions given by Nairn (1962). The sections treated with the antiserum were thoroughly washed with a phosphate buffer and then treated with goat's anti-rabbit gamma globulin serum, conjugated with fluorescein isothiocyanate, and washed again. The best results were obtained by 30 minutes' treatment of the sections with the fluorescent antibody.

The results are seen in Figs. 11-14, the first two showing the fixation of the fluorescent antibody in the direct method, and the second two in the sandwich method. Sections of two normal lungs were used as controls. Although the various nematodeantigens show some overlapping and no attempt was made to isolate individual antigens. The fact

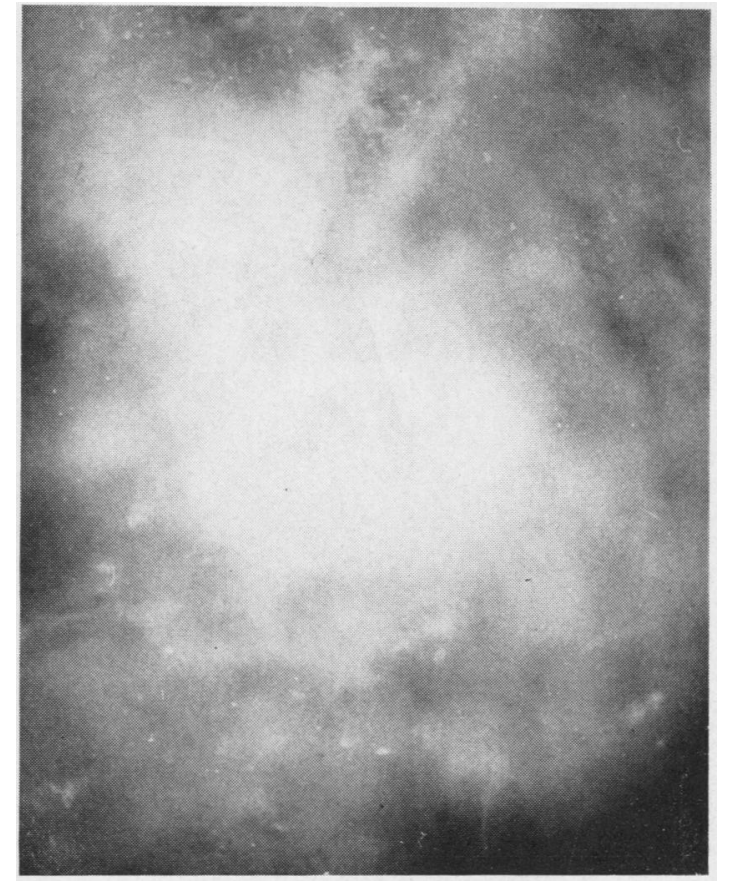

FIG. 11. Pulmonary granuloma. Section treated with fluorescein-isothiocyanate-labelled rabbit anti-ascaris serum. Direct method.

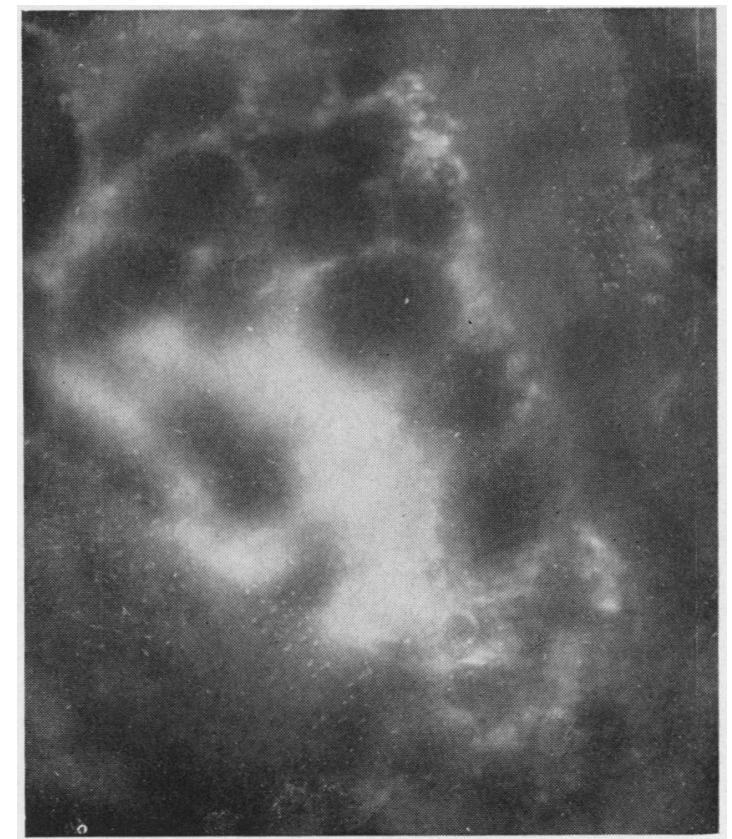

FIG. 12. Pulmonary granuloma. Section treated with fluorescein-isothiocyanate-labelled rabbit anti-ascaris serum. Direct method. 


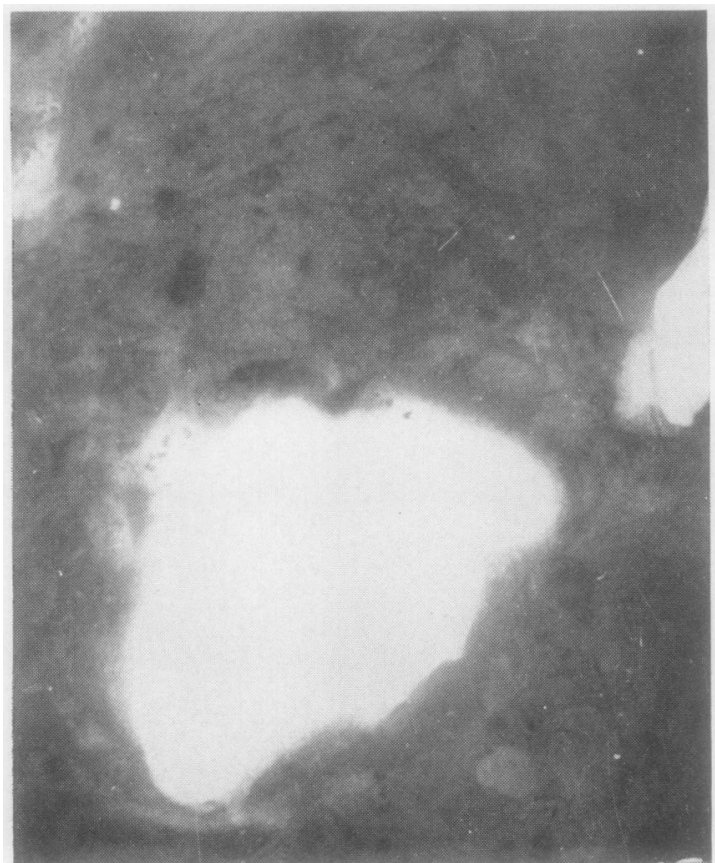

FIG. 13. Pulmonary granuloma. Sandwich method using rabbit anti-ascaris serum and fluorescein-isothiocyanatelabelled goat's anti-rabbit gamma globulin.

that in the past six years only ascaris, enterobius, and very occasionally trichiuris infestations were found in this hospital may be considered as proof that the fluorescent antibody technique demonstrated the presence of larvae of ascaris in the pulmonary granulomata.

We wish to thank Mrs. Beverage and Mrs. Brewer for technical assistance and Mr. K. Allen for the photographs.

\section{REFERENCES}

Beaver, P. C., and Danaraj, T. J. (1958). Amer. J. trop. Med. Hyg., 7, 100 .

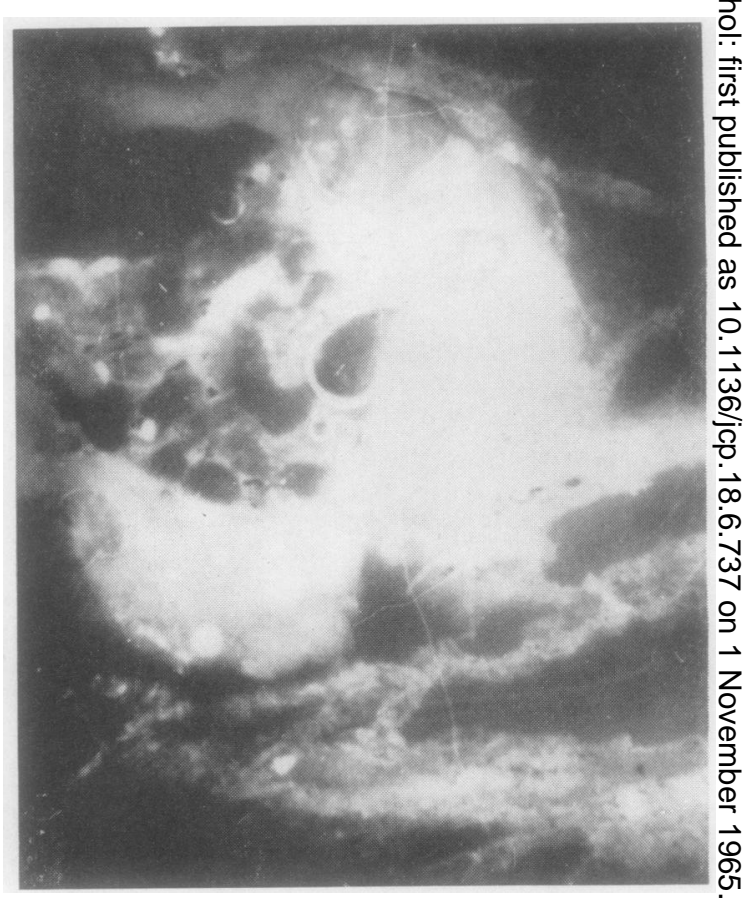

FIG. 14. Pulmonary granuloma. Sandwich method using rabbit anti-ascaris serum and fluorescein-isothiocyanate-O labelled goat's anti-rabbit gamma globulin.

Campbell, D. H. (1936). J. infect. Dis., 59, 266.

Chadwick, C. S., and Fothergill, J. E. (1962). Fluorochromes and their conjugation with proteins. In Fluorescent Protein Tracing, $\Rightarrow$ edited by R. C. Nairn, pp, 4-30 Livingstone, Edinburgh and London.

Jarrett, W. F. H., Jennings, F. W., McIntyre, W. I. M., Mulligan, W and Urquhart, G. M. (1960). Immunology, 3, 145.

Keller, A. E., Hillstrom, H. T., and Gass, R. S. (1932). J. Amer. med Ass., 99, 1249.

Kent, N. H. (1960). Exp. Parasit., 10, 313.

Nairn, R. C. (1962). Immunological tracing: general considerations In Fluorescent Protein Tracing, edited by R. C. Nairn, pp. 97127. Livingstone, Edinburgh and London.

Symposium: Some Biochemical and Immunological Aspects of HostParasite Relationships (1963), edited by Thomas C. Cheng. Ann. N.Y. Acad. Sci., 113, 1.

Takata, I. (1951). Kitasato Arch. exp. Med.. 234, 49. 